Check for updates

Cite this: RSC Adv., 2017, 7, 23246

Received 20th February 2017 Accepted 21st April 2017

DOI: $10.1039 / c 7 r a 02083 j$

rsc.li/rsc-advances

\section{Synthesis and excellent visible light photocatalysis performance of magnetic reduced graphene oxide/ $\mathrm{ZnO} / \mathrm{ZnFe}_{2} \mathrm{O}_{4}$ composites}

\begin{abstract}
Juhua Luo, (D) * Zhu Yan, Rongqi Liu, Jianguang Xu and Xu Wang
A novel magnetic $\mathrm{RGO} / \mathrm{ZnO} / \mathrm{ZnFe}_{2} \mathrm{O}_{4}$ composite was synthesized by a two step method. The phase formation, structure, morphology and chemical states were characterized by XRD, FESEM, TEM, FT-IR, Raman and XPS. The results showed that the composite consisted of a core-shell structure of $\mathrm{ZnO} /$ $\mathrm{ZnFe}_{2} \mathrm{O}_{4}$ coated with nearly transparent flake-like RGO. The photocatalytic effect of the composite was obviously better than that of single $\mathrm{ZnO}$ and $\mathrm{ZnO} / \mathrm{ZnFe}_{2} \mathrm{O}_{4}$. The optimal sample was $\mathrm{RGO} / \mathrm{ZnO} /$ $\mathrm{ZnFe}_{2} \mathrm{O}_{4}-3$ (the weight ratio of graphene to $\mathrm{ZnO} / \mathrm{ZnFe}_{2} \mathrm{O}_{4}$ was 3\%) which exhibited the best photocatalytic efficiency of $98.64 \%$ after 60 min under visible light irradiation for decolorization of $\mathrm{MB}$. The reusability of $\mathrm{RGO} / \mathrm{ZnO} / \mathrm{ZnFe}_{2} \mathrm{O}_{4}-3$ was excellent because of the magnetic $\mathrm{ZnFe}_{2} \mathrm{O}_{4}$ which can be recycled using a magnet or constant magnetic field.
\end{abstract}

\section{Introduction}

With the rapid development of industry, more and more industrial wastewater containing toxic organics is let out without any purification treatment, which has resulted in great harm to the health of human beings. ${ }^{1}$ Semiconductor photocatalytic materials such as $\mathrm{ZnO}$ have attracted lots of attention because of their cheap price, easy preparation methods, high chemical stability and excellent photocatalytic performance under UV-light. ${ }^{2,3}$ However, the development of single $\mathrm{ZnO}$ is limited by its narrow light response range, wide band gap (3.2 eV) and difficult recycling. ${ }^{4}$ To overcome these weaknesses, many researchers have focused on preparing composites containing $\mathrm{ZnO}$ and another magnetic semiconductor. Shao et al. ${ }^{5}$ have prepared magnetic recyclable $\mathrm{ZnFe}_{2} \mathrm{O}_{4} / \mathrm{ZnO}$ with a core-shell structure by a solvothermal method and alkali precipitation method. The result indicates that the photocatalytic activity of photocatalyst composite is higher than single $\mathrm{ZnO}$. Wang et al. ${ }^{6}$ reported magnetic $\mathrm{ZnFe}_{2} \mathrm{O}_{4} / \mathrm{ZnO}$ ( $\mathrm{ZFO} / \mathrm{ZnO})$ multi-porous nanotubes, when the molar ratio of $\mathrm{ZnFe}_{2} \mathrm{O}_{4}$ was $50 \%$, it exhibited the best photocatalytic efficiency of $99 \%$ after $150 \mathrm{~min}$ under the solar irradiation for the decolorization of $\mathrm{RhB}$. Xie et al. ${ }^{7}$ have provided a reliable method to synthesis Sr-doped $\mathrm{TiO}_{2} /$ magnetic $\mathrm{Ni}_{0.6} \mathrm{Zn}_{0.4} \mathrm{Fe}_{2} \mathrm{O}_{4}$ composites which not only has a high efficiency (90-100\%) and a good cycling performance ( $90 \%$ maintenance) for photodegradation of bisphenol A (BPA) under both UV and visible

School of Materials Science and Engineering, Yancheng Institute of Technology, Yancheng, Jiangsu Province, 224051, PR China. E-mail: luojuhua@163.com; Tel: $+86-515-88298867$ light irradiation, but also can be easily separated from water for reuse only by introducing an external magnetic field.

As we all known, the large bandgap of $\mathrm{ZnO}(\sim 3.2 \mathrm{eV})$ only allows it absorbing UV light for the required band gap excitation and charge carrier generation, limiting its light harvesting efficiency, since UV light only contributes $\sim 4 \%$ of the solar energy. ${ }^{8}$ To address this problem, combining $\mathrm{ZnO}$ with advanced carbon materials will be efficient solution. ${ }^{9}$ Graphene has fascinating properties, such as a large surface area, good mechanical flexibility, high chemical stability, and unique electronic properties. ${ }^{10}$ Graphene is considered an ideal substrate to form graphene-based nanocomposites by anchoring nanoparticles on the layer surface, which make the resulting nanocomposite an efficient photocatalyst, because of the enhanced adsorption on the catalyst, non-aggregation of nanoparticles, an extended light-absorption range, and a significantly less recombination of photogenerated electronhole pairs. ${ }^{11}$ Zhang et al. ${ }^{12}$ have synthesised the ZnO nanorod/ graphene composite by a hydrothermal method. They found that the composite has good photocatalytic performance resulting from high surface areas and electron transfer ability of graphene which hinders the quick combination of photogenerated electron-hole. Fu et al. ${ }^{13}$ synthesized $\mathrm{ZnFe}_{2} \mathrm{O}_{4} / \mathrm{RGO}$ for the removal of methylene blue in the presence of $\mathrm{H}_{2} \mathrm{O}_{2}$ under visible-light irradiation.

Inspired of above truth, the $\mathrm{ZnO} / \mathrm{ZnFe}_{2} \mathrm{O}_{4}$ nanocomposite was prepared by hydrothermal method and then deposited on the surface of graphene to obtain the $\mathrm{RGO} / \mathrm{ZnO} / \mathrm{ZnFe}_{2} \mathrm{O}_{4}$ composite. The structures and morphologies were investigated. The possible mechanism of photocatalysis was also further discussed. 


\section{Experimental}

\subsection{Synthesis of $\mathrm{ZnFe}_{2} \mathrm{O}_{4}$}

$\mathrm{ZnFe}_{2} \mathrm{O}_{4}$ was prepared by a hydrothermal method. $\left(\mathrm{CH}_{3}-\right.$ $\mathrm{COO})_{2} \mathrm{Zn}$ and $\mathrm{FeCl}_{3}$ (Analytical Reagent) were dissolved in distilled water in stoichiometric proportion along with moderate hydrazine hydrate solution. The mixture was magnetically stirred for $30 \mathrm{~min}$ and transferred to a Teflon-lined stainless steel autoclave and heated at $180{ }^{\circ} \mathrm{C}$ for $12 \mathrm{~h}$. The product was washed by distilled water and ethanol several times and dried at $60{ }^{\circ} \mathrm{C}$ in a vacuum oven.

\subsection{Synthesis of $\mathrm{ZnO} / \mathrm{ZnFe}_{2} \mathrm{O}_{4}$ composite}

A certain amount of $\mathrm{ZnFe}_{2} \mathrm{O}_{4}$ and $\left(\mathrm{CH}_{3} \mathrm{COO}\right)_{2} \mathrm{Zn}$ were dissolved in $30 \mathrm{~mL}$ ethanol and ultra-sonicated for $1 \mathrm{~h}$ to obtain fine dispersion. The $30 \mathrm{~mL}$ ethanol solution containing moderate $\mathrm{NaOH}$ (the molar ratio of $\mathrm{NaOH}$ and $\left(\mathrm{CH}_{3} \mathrm{COO}\right)_{2} \mathrm{Zn}$ was $2: 1$ ) was added into the dispersion drop by drop and stirred for $1 \mathrm{~h}$. The mixture was transferred to a Teflon-lined stainless steel autoclave and heated at $90^{\circ} \mathrm{C}$ for $10 \mathrm{~h}$. The product was washed by distilled water, ethanol several times and was dried at $60{ }^{\circ} \mathrm{C}$ in a vacuum oven. The obtained $\mathrm{ZnO} / \mathrm{ZnFe}_{2} \mathrm{O}_{4}$ composite was marked as $\mathrm{Z} / \mathrm{ZF}$.

\subsection{Synthesis of reduce graphene oxide $/ \mathrm{ZnO} / \mathrm{ZnFe}_{2} \mathrm{O}_{4}$ composite}

The preparation of reduced graphene oxide $/ \mathrm{ZnO} / \mathrm{ZnFe}_{2} \mathrm{O}_{4}$ composite was based on a facile one-pot method. Typically, a certain amount graphite oxide powder was dispersed $100 \mathrm{~mL}$ deionized water and ultra-sonicated for $2 \mathrm{~h}$ to produce GO solution. (The graphite oxide was synthesized by modified Hummers method. ${ }^{14}$ ) Then $0.4 \mathrm{~g} \mathrm{ZnO} / \mathrm{ZnFe}_{2} \mathrm{O}_{4}$ was added into the GO solution and stirred for $3 \mathrm{~h}$. After that, moderate hydrazine hydrate was added to the mixture with constant stirring at $95{ }^{\circ} \mathrm{C}$ for $12 \mathrm{~h}$. The resulting precipitate was filtrated, washed with distilled water and ethanol repeatedly and dried under vacuum at $60{ }^{\circ} \mathrm{C}$ for about $12 \mathrm{~h}$. The samples with different weight ratios of 1,3 , and $5 \%$ of graphene and $\mathrm{ZnO} /$ $\mathrm{ZnFe}_{2} \mathrm{O}_{4}$ were denoted as RGO/Z/ZF-1, RGO/Z/ZF-3, RGO/Z/ZF-5, respectively.

\subsection{Characterization}

The resulting powder was characterized by X-ray diffraction (XRD) using a diffractometer (RIGAKU, model D/max) with $\mathrm{CuK}_{\alpha}$ radiation of wavelength $\lambda=0.1540598 \mathrm{~nm}$. Fourier transform infrared spectra (FT-IR) were carried out using the infrared spectrophotometer (NICOLET, model NEXUS-670) in the range from 4000 to $400 \mathrm{~cm}^{-1}$ with a resolution of $1 \mathrm{~cm}^{-1}$. Raman spectra were measured using a Laser Raman spectroscope (Thermo Fisher, model DXR) at a $633 \mathrm{~nm}$ wavelength incident laser light. The morphologies were studied with a field emission scanning electron microscope (JEOL, model JSM$7001 \mathrm{~F}$ ) and a transmission electron microscope (JEOL, model JEM-2001). The chemical states were investigated by X-ray photoelectron spectroscopy (XPS, model ESCALAB-250Xi). BET surface areas were calculated from $\mathrm{N}_{2}$ adsorption data that were obtained using specific surface area analyzer (Quantachrome, model Autosorb-1) at liquid $\mathrm{N}_{2}$ temperature. Before the measurement, the sample was degassed for $12 \mathrm{~h}$ at $150{ }^{\circ} \mathrm{C}$. Magnetization measurements were taken at room temperature (293 K) using a vibrating sample magnetometer (LDJ, model 9600-1).

\subsection{Photocatalytic testing}

Photocatalytic activities of the obtained photocatalysts were evaluated by the degradation of $\mathrm{MB}$ in aqueous solution. A $500 \mathrm{~W}$ Xenon lamp with suitable cutoff filters $(\lambda>420 \mathrm{~nm})$ was employed as the light source. For each photocatalytic testing, $50 \mathrm{mg}$ photocatalyst was dispersed into $100 \mathrm{~mL}$ of $\mathrm{MB}$ aqueous solution with the concentration of $10 \mathrm{mg} \mathrm{L}^{-1}$ with or without $0.5 \mathrm{M} \mathrm{CH}_{3} \mathrm{OH}$ as the hole scavenger. The suspension solution was magnetically stirred in the dark for $30 \mathrm{~min}$ to reach the absorption-desorption equilibrium. Then the suspension solution was irradiated by Xenon lamp with continuous stirring. At the given intervals, $5 \mathrm{~mL}$ of the aliquots was sampled and analyzed by recording variations in the absorption band (664 $\mathrm{nm}$ ) in the UV-vis spectra (UV2300II) of MB.

\section{Results and discussion}

\subsection{Structure and morphology analysis}

The XRD patterns of the samples are presented in Fig. 1. It is clear that the peak at $2 \theta=10.96^{\circ}$ is attributed to (002) plane of GO (Fig. 1a) and there is no peak of natural graphite at $2 \theta=$ $26.51^{\circ}$, which indicates the GO is synthesized. ${ }^{15}$ The interplanar spacing of GO can be calculated by Bragg equation: $2 d \sin \theta=$ $n \lambda$, where $d$ is the interplanar spacing, $\lambda$ is X-ray wavelength and $\theta$ is the diffraction angle. The interplanar spacing of GO $(d=$ $0.85 \mathrm{~nm})$ is obviously bigger than that of natural graphite $(d=$ $0.334 \mathrm{~nm}$ ), which indicates the intercalation of water molecules and generation of oxygenated functional groups such as epoxy

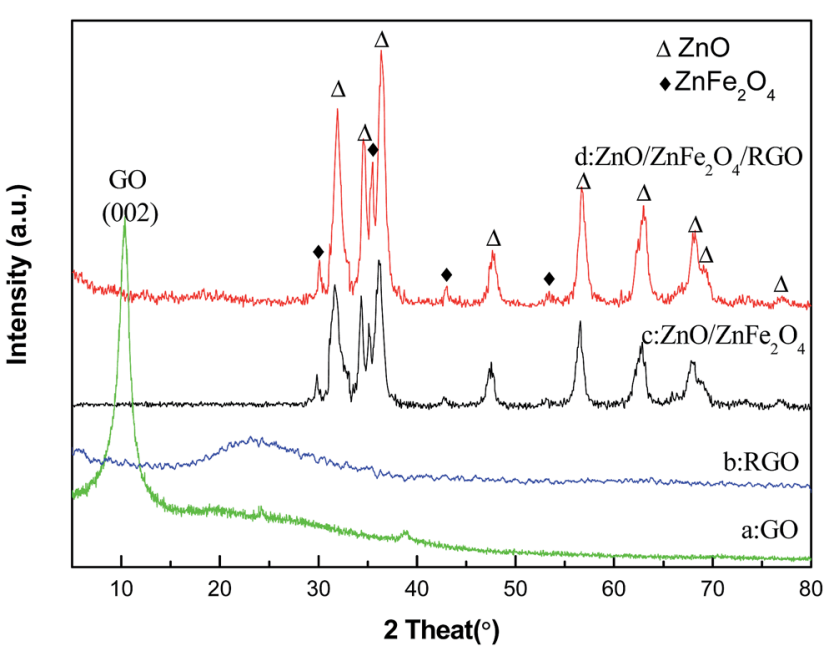

Fig. 1 XRD patterns of (a) GO, (b) RGO, (c) Z/ZF composite and (d) RGO/Z/ZF-1 composite. 
and hydroxyl group between the inter-galleries of the graphite sheets during high oxidation. ${ }^{16}$ A broad peak at $2 \theta=24.60^{\circ}$ is observed and the peak of GO is vanished in Fig. 1b, which suggests the GO is reduced mostly by hydrazine hydrate and RGO is prepared successfully. As shown in Fig. 1c, the peaks at $2 \theta=31.65^{\circ}, 34.29^{\circ}, 36.10^{\circ}, 47.35^{\circ}, 56.40^{\circ}, 62.65^{\circ}, 67.70^{\circ}$ and $68.81^{\circ}$ are corresponding to the (100), (002), (101), (102), (110), (103), (112), (201) and (202) lattice plane of ZnO. Meanwhile, the peaks at $2 \theta=30.04^{\circ}, 35.28^{\circ}, 42.96^{\circ}$ and $56.34^{\circ}$ are corresponding to the (220), (311), (400) and (511) lattice plane of $\mathrm{ZnFe}_{2} \mathrm{O}_{4}$. Based on this, we can confirm that the $\mathrm{Z} / \mathrm{ZF}$ composite is synthesized successfully by hydrothermal method. In Fig. 1d, characteristic peaks of $\mathrm{Z} / \mathrm{ZF}$ can be seen, which indicates the existence of $\mathrm{Z} / \mathrm{ZF}$ in $\mathrm{RGO} / \mathrm{Z} / \mathrm{ZF}-1$. However, the peaks of RGO do not appear in the pattern. It may be attributed to the low contents of RGO in the ternary composite. So, some other characterization methods were utilized to confirm the existence of RGO in RGO/Z/ZF-1 composite.

The morphology and structure of the obtained samples were investigated by FESEM and TEM. Fig. 2a shows the representative SEM image of these $\mathrm{ZnFe}_{2} \mathrm{O}_{4}$, which suggests that samples contained uniform nanospheres with an average grain size of $400 \mathrm{~nm}$. As shown in Fig. $2 \mathrm{~b}$ and c, the Z/ZF displays spherical with uniform size and smooth surface. The transparent sheets with plenty of wrinkles are R-GO and the $\mathrm{Z} / \mathrm{ZF}$ is
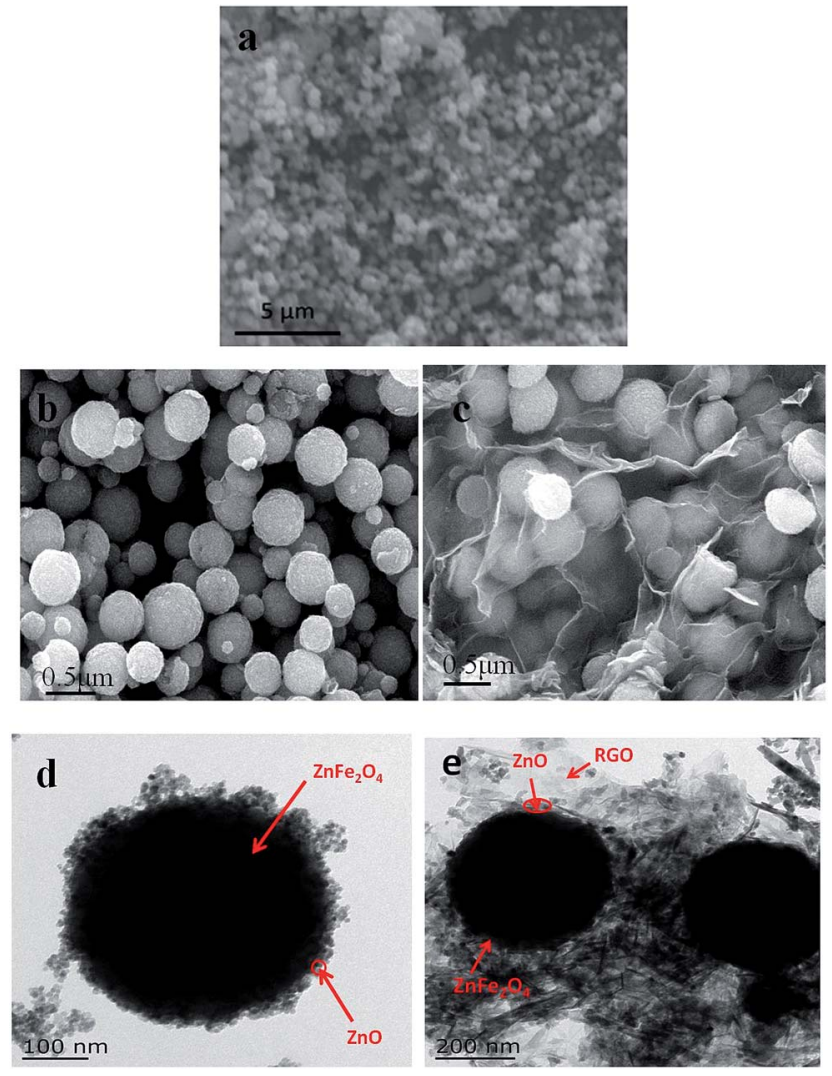

Fig. 2 SEM image of (a) Z/ZF composite, FESEM images of (b) Z/ZF composite and (c) RGO/Z/ZF-1 composite, TEM images of (d) Z/ZF composite and (e) RGO/Z/ZF-1 composite. covered by these flake-like R-GO sheets. More detailed structures of samples are given in TEM images. From Fig. 2d, we can observe that the $\mathrm{Z} / \mathrm{ZF}$ has clear core-shell structure. The $\mathrm{ZnFe}_{2} \mathrm{O}_{4}$ was coated by $\mathrm{ZnO}$ with a thickness of $20 \mathrm{~nm}$. According to the TEM image in Fig. 2e, the RGO/Z/ZF-1 composite can be seen more clearly, the tint parts were RGO and the dark parts were Z/ZF. Spherical core-shell Z/ZF particles were covered by transparent RGO sheets. Hence, results of FESEM and TEM confirm the existence of RGO and Z/ZF in the ternary composite, which agrees with the XRD analysis.

Fig. 3 shows the FT-IR spectra of the samples. The peaks of GO that appearing at 1730, 1611, 1420, 1225 and $1045 \mathrm{~cm}^{-1}$ are assigned to $\mathrm{C}=\mathrm{O}$ stretching vibration of carbonyl and carbonyl groups, conjugate $\mathrm{C}=\mathrm{C}$ skeletal stretching vibration of unoxidized graphite domains or the remaining $\mathrm{sp}^{2}$ carbon character of graphite, O-H stretching vibration of carbonyl, C-O stretching vibration of epoxide and $\mathrm{C}-\mathrm{O}$ stretching vibration from alkoxy groups, respectively. ${ }^{17-21}$ For RGO, the absence of most bands related to the above oxygen-containing functional groups demonstrates that the GO was reduced mostly by hydrazine hydrate. The peak at $1580 \mathrm{~cm}^{-1}$ is attributed to the conjugate $\mathrm{C}=\mathrm{C}$ skeletal stretching vibration of graphite. Comparing $\mathrm{Z} / \mathrm{ZF}$ with $\mathrm{RGO} / \mathrm{Z} / \mathrm{ZF}-1$, the peaks at 545 and $439 \mathrm{~cm}^{-1}$ are corresponding to the stretching vibrations of the $\mathrm{Fe}-\mathrm{O}$ bonds in octahedral positions and the stretching vibrations of the $\mathrm{Zn}-\mathrm{O}$ bonds in tetrahedral positions respectively, ${ }^{22}$ which suggest the existence of $\mathrm{Z} / \mathrm{ZF}$ in ternary composite. Furthermore, a weak characteristic peak appearing at around $1580 \mathrm{~cm}^{-1}$ was due to the conjugate $\mathrm{C}=\mathrm{C}$ skeletal stretching vibration of $\mathrm{RGO}$ in the RGO/Z/ZF-1 composite.

The Raman spectra of the samples are given in Fig. 4. From the Fig. 4a and b, we can observe that there are two strong Raman peaks at around 1345 and $1600 \mathrm{~cm}^{-1}$ attributing to the D and G bands, respectively. The $\mathrm{D}$ band is assigned to the vibration of $\mathrm{sp}^{3}$ carbon atoms of disordered graphite, ${ }^{23}$ which corresponds to a first-order zone boundary phonon mode associated with defects

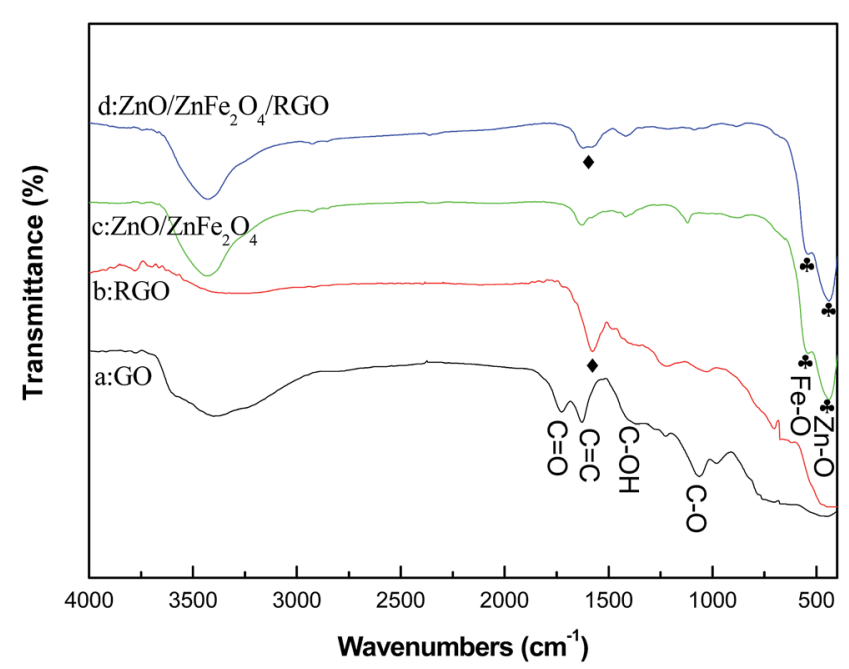

Fig. 3 FT-IR spectra of (a) GO, (b) RGO, (c) Z/ZF composite and (d) RGO/Z/ZF-1 composite. 

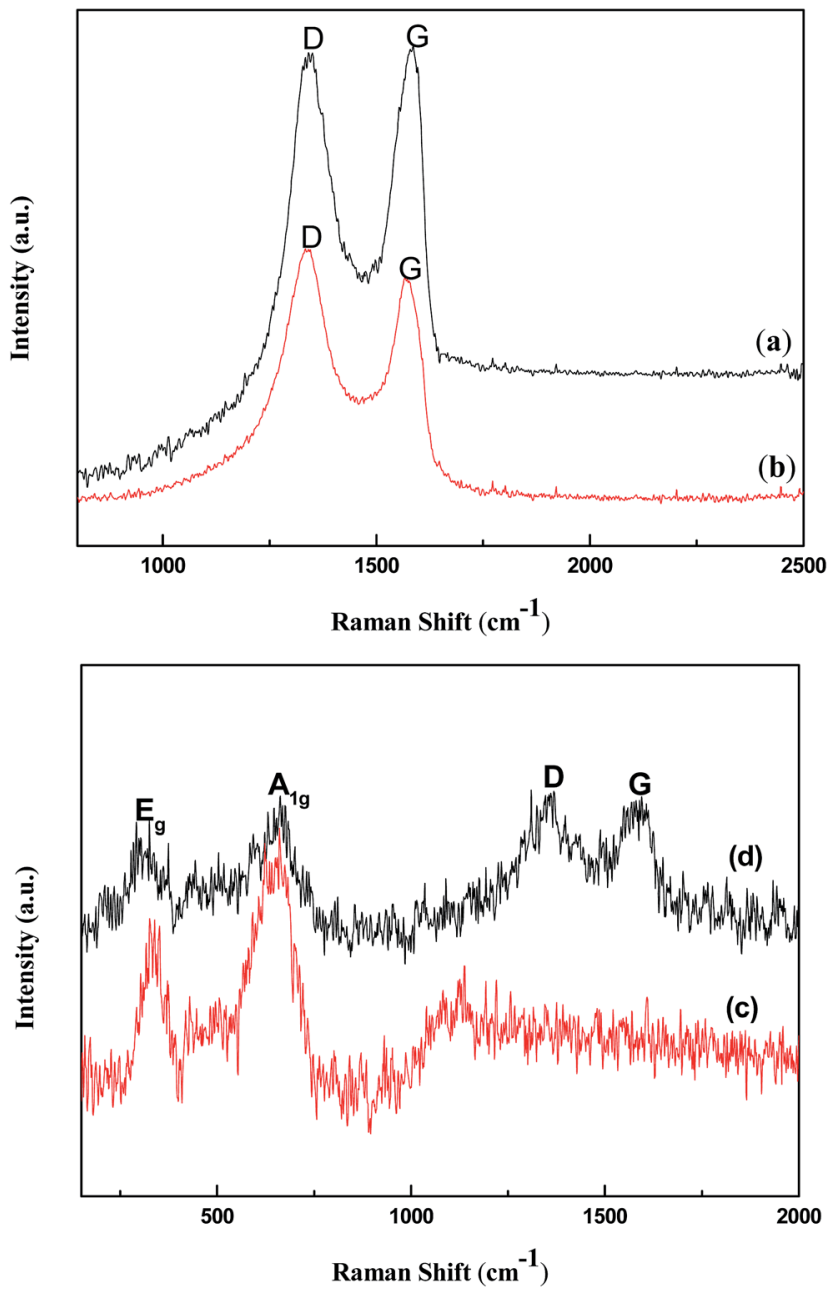

Fig. 4 Raman spectra of (a) GO, (b) RGO, (c) Z/ZF composite and (d) RGO/Z/ZF-1 composite.

in the graphene or graphene edge. The $\mathrm{G}$ band is mainly attributed to the in-plane vibration of $\mathrm{sp}^{2}$ carbon atoms in a $2 \mathrm{D}$ hexagonal lattice. ${ }^{24}$ Furthermore, the intensity ratio of $\mathrm{D}$ band to $\mathrm{G}$ band $\left(I_{\mathrm{D}} / I_{\mathrm{G}}\right)$ is usually used to measure the graphitization degree of carbon materials. ${ }^{25}$ In this study, the $I_{\mathrm{D}} / I_{\mathrm{G}}$ of GO and RGO are 0.95 and 1.11 , respectively. The increase in value of $I_{\mathrm{D}} / I_{\mathrm{G}}$ suggests that a decrease in the average size of the $\mathrm{sp}^{2}$ domains upon reduction of the GO and more defects has been generated. ${ }^{26}$ As shown in Fig. 4c, the peak at around 337, 664 and $443 \mathrm{~cm}^{-1}$ are regard as the $\mathrm{E}_{\mathrm{g}}, \mathrm{A}_{1 \mathrm{~g}}$ modes of $\mathrm{ZnFe}_{2} \mathrm{O}_{4}$ and characteristic peak of $\mathrm{ZnO}$, respectively. ${ }^{27,28}$ From Fig. $4 \mathrm{~d}$, it is seen that the Raman spectrum of $\mathrm{RGO} / \mathrm{Z} / \mathrm{ZF}-1$ composite contains the characteristic peaks of RGO, $\mathrm{ZnO}$ and $\mathrm{ZnFe}_{2} \mathrm{O}_{4}$, which indicates the successful synthesis of $\mathrm{RGO} / \mathrm{Z} / \mathrm{ZF}-1$ composites.

The chemical states of elements in $\mathrm{RGO} / \mathrm{Z} / \mathrm{ZF}-1$ are further investigated by XPS. The wide scan XPS spectrum of RGO/Z/ZF-1 in Fig. 5a shows photoelectron lines at a binding energy of about 286, 531, 710 and $1022 \mathrm{eV}$ attributed to C 1s, O 1s, Fe 2p and $\mathrm{Zn} 2 \mathrm{p}$, respectively. The peaks of $\mathrm{Zn} 2 \mathrm{p}_{1 / 2}$ and $\mathrm{Zn} 2 \mathrm{p}_{3 / 2}$ are located at 1044.9 and $1021.8 \mathrm{eV}$, which indicates that the chemical state of $\mathrm{Zn}$ is +2 in ternary composite. ${ }^{29}$ The Fe $2 \mathrm{p}_{1 / 2}$ appears at $724.8 \mathrm{eV}$ and the peak at $711.7 \mathrm{eV}$ is attributed to $\mathrm{Fe}$ $2 \mathrm{p}_{3 / 2}$ level. In addition, a satellite vibration peak is located at $718.1 \mathrm{eV}$. It demonstrates that $\mathrm{Fe}^{3+}$ exists in the $\mathrm{RGO} / \mathrm{Z} / \mathrm{ZF}-1 .^{30}$ The peaks of $\mathrm{O} 1 \mathrm{~s}$ appearing at 533.5, 531.9 and $530.3 \mathrm{eV}$ were corresponding to $\mathrm{C}-\mathrm{O}-\mathrm{C}$ of graphene, hydrogen bond in absorbed water and the band of $\mathrm{M}-\mathrm{O}$ ( $\mathrm{M}$ represents metal) in $\mathrm{Z} /$ $\mathrm{ZF}^{31-33}$ As shown in the high resolution XPS spectra of $\mathrm{C} 1 \mathrm{~s}$, the peaks at $288.5,285.3$ and $284.5 \mathrm{eV}$ are due to the $\mathrm{C}$ in $\mathrm{C}=\mathrm{O}, \mathrm{C}-\mathrm{O}$ and $\mathrm{C}=\mathrm{C} / \mathrm{C}-\mathrm{C}$. Meanwhile, it can be seen that the intensity of $\mathrm{C}=\mathrm{O}$ and $\mathrm{C}-\mathrm{O}$ are obviously lower than $\mathrm{C}-\mathrm{C}$ and $\mathrm{C}=\mathrm{C}$, which indicates that containing oxygen functional groups in GO has been reduced by hydrazine hydrate. ${ }^{34}$ The result of XPS analysis further confirms the synthesis of RGO/Z/ZF-1.

\subsection{Photocatalytic performance and mechanism analysis}

To evaluate the photocatalytic activities of $\mathrm{RGO} / \mathrm{Z} / \mathrm{ZF}$ photocatalysts under the visible light irradiation, $\mathrm{MB}$ is employed as a model pollutant. As contrast, the photocatalytic activity of pure $\mathrm{ZnO}$ and $\mathrm{Z} / \mathrm{ZF}$ photocatalysts are also carried out at the same conditions. Fig. 6 showed the photocatalytic degradation of MB under different samples at room temperature. There is nearly no degradation of MB without photocatalysts. The photocatalytic degradation of $\mathrm{MB}$ is very weaker only under the help of $\mathrm{ZnO}$ compared with that of $\mathrm{Z} / \mathrm{ZF}$. The possible reasons were: firstly, $\mathrm{ZnO}$ (energy gap $=3.37 \mathrm{eV}$ ) is only excited by UV light irradiation rather than visible light irradiation. $\mathrm{ZnFe}_{2} \mathrm{O}_{4}$ nanoparticles with bandgap of $1.8 \mathrm{eV}$ are in principle a good visible light photocatalysts. ${ }^{35}$ Secondly, the Z/ZF has a core-shell structure which can provide a heterojunction structure. The heterojunction structure promotes the separation of photogenerated electrons and holes, improving the photocatalysis activity. ${ }^{36}$ After addition of RGO, the photocatalytic degradation effect of $\mathrm{RGO} / \mathrm{Z} / \mathrm{ZF}$ is better than that of pure $\mathrm{ZnO}$ and $\mathrm{Z} / \mathrm{ZF}$, the $\mathrm{RGO} / \mathrm{Z} / \mathrm{ZF}-3$ presents the best photocatalytic activity (the final $c$ / $c_{0}$ is minimum). In the $\mathrm{RGO} / \mathrm{Z} / \mathrm{ZF}$ composite, the RGO plays a role to adsorb $\mathrm{MB}$ by the $\pi-\pi$ stacking. The RGO with lower Fermi level can preferentially accept the photogenerated electrons, which can reduce the recombination of the photogenerated electrons and holes produced by $\mathrm{Z} / \mathrm{ZF}{ }^{37}$ The synergistic effect of three components can markedly improve the photocatalytic activity of composite. The Fig. 7 gives the temporal evolution of the absorption spectra during the photo degradation of $\mathrm{MB}$ for $\mathrm{RGO} / \mathrm{Z} / \mathrm{ZF}-3$. It can be seen that the intensity of the absorption peaks at $664 \mathrm{~nm}$ gradually decreased with irradiation time during MB degradation. It is observed that the peaks nearly completely disappear when the photocatalytic degradation process for MB is carried out for $60 \mathrm{~min}$.

In order to make a further investigation on photocatalytic process, the kinetic behavior of photocatalytic degradation needs to be studied. Generally, the kinetic process of photocatalysis is described by pseudo-first-order reaction equation: ${ }^{38}$

$$
\ln \frac{C_{0}}{C_{t}}=K t
$$

where $C_{0}$ and $C_{t}\left(\mathrm{mg} \mathrm{L}^{-1}\right)$ are the concentration of $\mathrm{MB}$ at the $t=$ 0 and time $t(\mathrm{~min})$, respectively. $K\left(\mathrm{~min}^{-1}\right)$ is the rate constants 

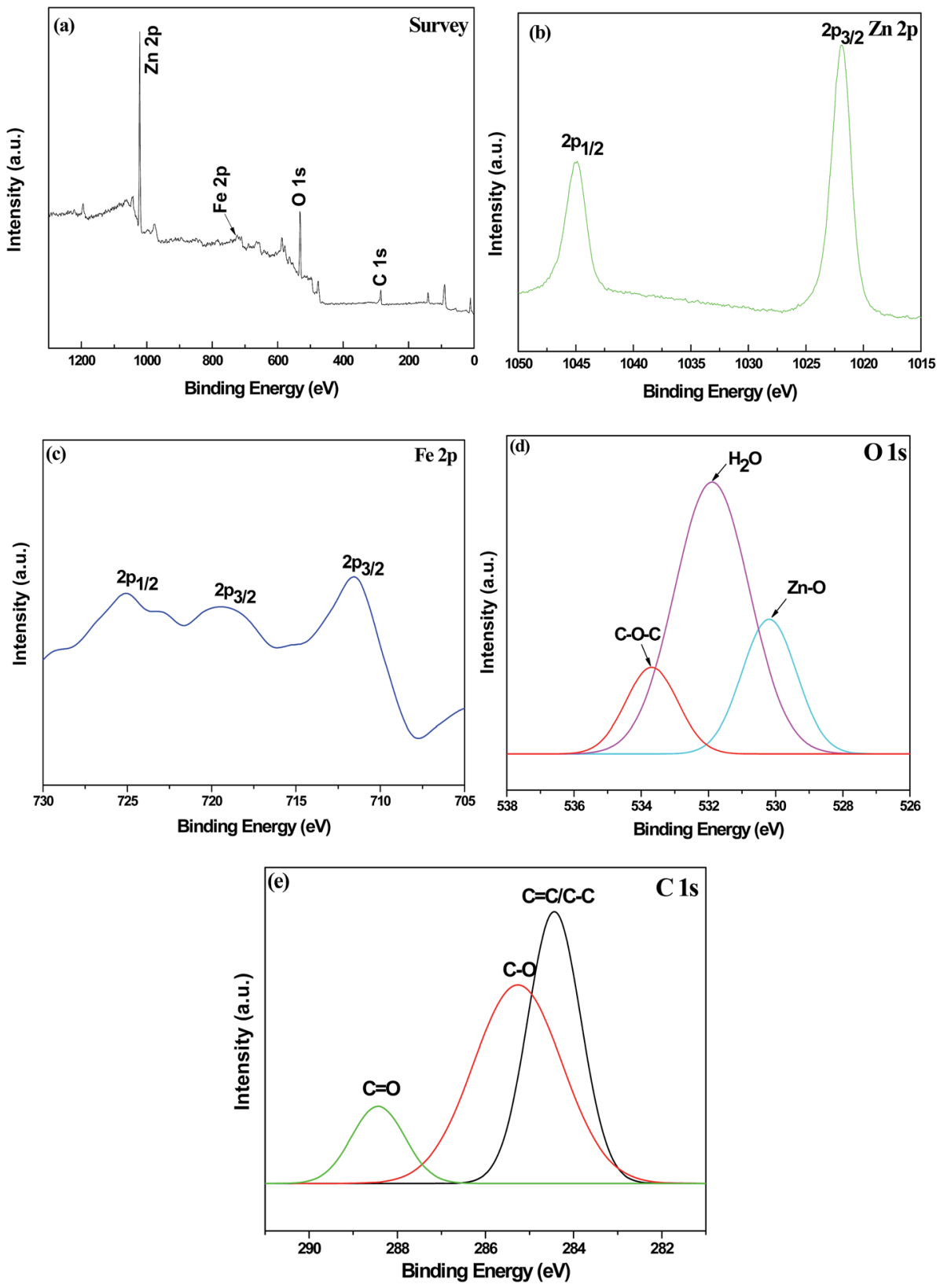

Fig. 5 XPS spectra of RGO/Z/ZF-1 (a) full spectrum, (b) Zn 2p, (c) Fe 2p, (d) O 1s and (e) C 1s.

which has a positive correlation with the photocatalytic activity. The fitting results of photocatalytic degradation of $\mathrm{MB}$ are shown in Fig. 8 and Table 1. It can be seen from the results that the RGO/Z/ZF-3 has the fastest rate of rate constants $(K=$ $\left.0.05652 \mathrm{~min}^{-1}\right)$ and better fitting correlation index $\left(R^{2}=0.986\right)$, which indicates that the RGO/Z/ZF-3 has the best photocatalytic activity.

As we all known, if the energy of irradiate light is greater than the photoabsorption threshold value of photocatalyst, the photogenerated electron-hole pairs will be produced in photocatalyst. Then the generated electrons will combine with waterdissolved $\mathrm{O}_{2}$ to form superoxide radical anion $\left(\mathrm{O}_{2}{ }^{\cdot-}\right)$, the generated holes will react with the surface-absorbed $\mathrm{OH}$ groups to form ${ }^{\circ} \mathrm{OH}$ radicals. These photoinduced $\mathrm{O}_{2}{ }^{\cdot-}$ and ${ }^{\circ} \mathrm{OH}$ have strong oxidability which can effectively decompose the organic dye of MB to final harmless degradation products ${ }^{39,40}$ The reaction pathways as follows:

$$
\begin{gathered}
\mathrm{ZnFe}_{2} \mathrm{O}_{4}+h \nu \rightarrow \mathrm{ZnFe}_{2} \mathrm{O}_{4}\left(\mathrm{e}^{-}+\mathrm{h}^{+}\right) \\
\mathrm{ZnO}+\mathrm{e}^{-} \rightarrow \mathrm{ZnO}\left(\mathrm{e}^{-}\right) \\
\mathrm{RGO}+\mathrm{e}^{-} \rightarrow \mathrm{RGO}\left(\mathrm{e}^{-}\right) \\
\mathrm{O}_{2}+\mathrm{ZnO}\left(\mathrm{e}^{-}\right) \rightarrow \mathrm{O}_{2}{ }^{--} \\
\mathrm{O}_{2}+\mathrm{RGO}\left(\mathrm{e}^{-}\right) \rightarrow \mathrm{O}_{2}{ }^{-} \\
\mathrm{ZnFe}_{2} \mathrm{O}_{4}\left(\mathrm{~h}^{+}\right)+\mathrm{OH}^{-} \rightarrow \mathrm{ZnFe}_{2} \mathrm{O}_{4}{ }^{\cdot} \mathrm{OH}
\end{gathered}
$$




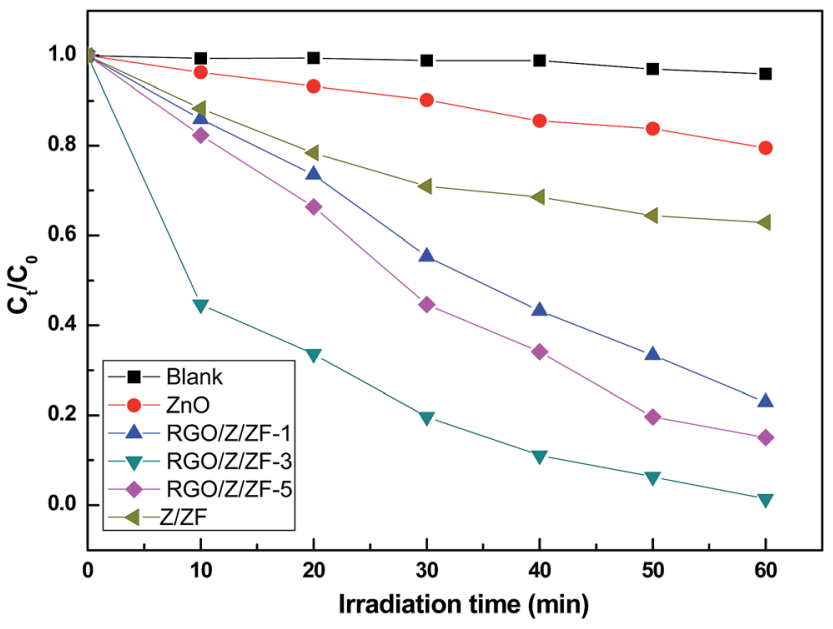

Fig. 6 Methylene blue decolourization of different photocatalysts.

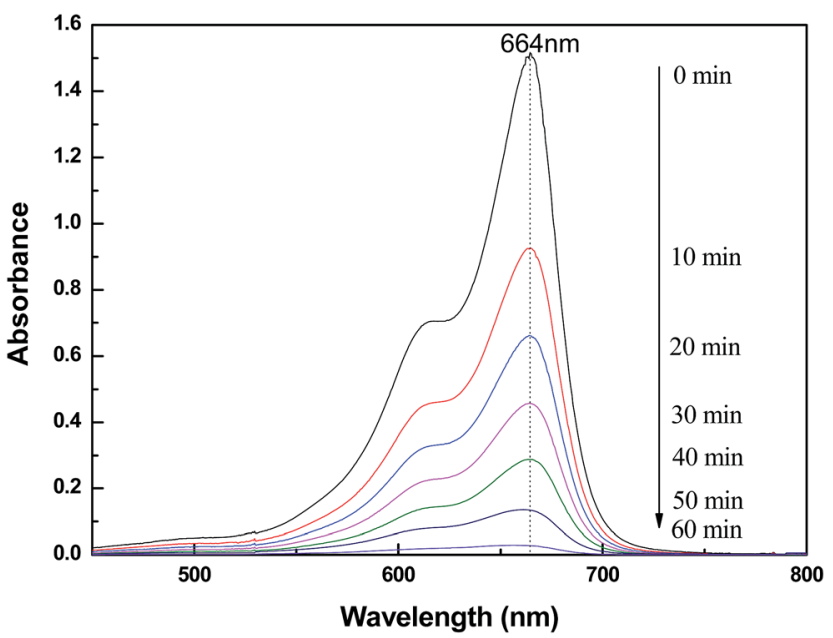

Fig. 7 Absorption spectra of $M B$ taken at different photocatalytic degradation times with RGO/Z/ZF-3 as photocatalysts.

$$
\mathrm{O}_{2}{ }^{\cdot-}+{ }^{\cdot} \mathrm{OH}+\mathrm{MB} \rightarrow \text { degradation products }
$$

The possible mechanism of visible light photocatalysis can be illustrated by Fig. 9. It is known to us that the conduction band ( $\mathrm{CB}=-1.54 \mathrm{~V} v s$. NHE) and valance band $(\mathrm{VB}=0.38 \mathrm{~V} v s$. $\mathrm{NHE})^{41}$ of $\mathrm{ZnFe}_{2} \mathrm{O}_{4}$ are both negative than the conduction band $(\mathrm{CB}=-0.1 \mathrm{~V} v s$. $\mathrm{NHE})$ and valance band $(\mathrm{VB}=3.2 \mathrm{~V} v s . \mathrm{NHE})^{42}$ of $\mathrm{ZnO}$, which leads to the type II band alignment of $\mathrm{Z} / \mathrm{ZF}{ }^{43,44}$ Upon visible light irradiation, the partial photogenerated electrons from conduction band of $\mathrm{ZnFe}_{2} \mathrm{O}_{4}$ are transferred to the conduction band of $\mathrm{ZnO}$, oppositely, the photogenerated holes lefted in the valance band of $\mathrm{ZnFe}_{2} \mathrm{O}_{4}$. The photogenerated electrons and holes can be effectively separated. ${ }^{45}$ The photogenerated electrons transferring into the conduction band of $\mathrm{ZnO}$ and holes left in the valance band of $\mathrm{ZnFe}_{2} \mathrm{O}_{4}$ can be captured by water-dissolved $\mathrm{O}_{2}$ and $\mathrm{OH}$ groups to form $\mathrm{O}_{2}{ }^{--}$and ${ }^{\circ} \mathrm{OH}$ respectively because of the more positive $E\left(\mathrm{O}_{2} / \mathrm{O}_{2}{ }^{\cdot-}\right)(0.0 \mathrm{~V}$ vs. $\mathrm{NHE})^{46}$ and $E\left(\mathrm{OH} /{ }^{\circ} \mathrm{OH}\right)(2.87 \mathrm{~V}$ vs. NHE $),{ }^{47}$ which can

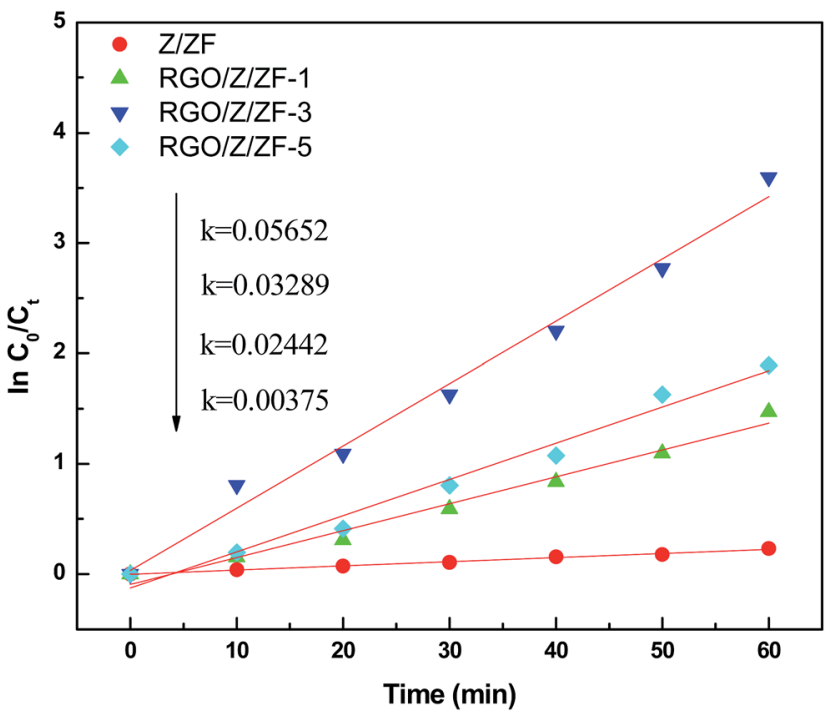

Fig. 8 Linear fitting curve of different photocatalytic degradation of methylene blue.

Table 1 The fitting results of first-order kinetic model for different samples

\begin{tabular}{llll}
\hline & \multicolumn{3}{l}{ Liner fitting of first-order kinetics reaction } \\
\cline { 2 - 4 } Samples & Equation & $R^{2}$ & $K\left(\mathrm{~min}^{-1}\right)$ \\
\hline $\mathrm{Z} / \mathrm{ZF}$ & $\ln \left(c_{0} / c_{t}\right)=0.00375 t$ & 0.9926 & 0.00375 \\
$\mathrm{RGO} / \mathrm{Z} / \mathrm{ZF}-1$ & $\ln \left(c_{0} / c_{t}\right)=0.02442 t$ & 0.9776 & 0.02442 \\
$\mathrm{RGO} / \mathrm{Z} / \mathrm{ZF}-3$ & $\ln \left(c_{0} / c_{t}\right)=0.05652 t$ & 0.986 & 0.05652 \\
$\mathrm{RGO} / \mathrm{Z} / \mathrm{ZF}-5$ & $\ln \left(c_{0} / c_{t}\right)=0.03289 t$ & 0.9763 & 0.03289
\end{tabular}

effectively decompose MB to final harmless small molecules. Further evidence is provided by adding $\mathrm{CH}_{3} \mathrm{OH}$, which is a typical holes cavenger in aqueous solution. ${ }^{45}$ Fig. 10 shows degradation efficiency of $\mathrm{RGO} / \mathrm{ZnO} / \mathrm{ZnFe}_{2} \mathrm{O}_{4}-3$ with or without $\mathrm{CH}_{3} \mathrm{OH}$ when the photocatalytic degradation process is carried out for $60 \mathrm{~min}$. Low degradation efficiency is observed after adding $\mathrm{CH}_{3} \mathrm{OH}$. This result confirms that both electrons and holes can attribute to the degradation process. Meanwhile, RGO also plays an important role in ternary composite. Firstly, partial photogenerated electrons from conduction band of $\mathrm{ZnFe}_{2} \mathrm{O}_{4}$ are also readily transferred to the graphene nanosheets because of more positive conduction band $(\mathrm{CB}=-0.75 \mathrm{~V} v s$. $\mathrm{NHE})^{48}$ and more efficient electron transportation of graphene, which can prohibit the recombination of electron-hole pairs. ${ }^{37,41}$ Secondly, the unique structure of RGO provides the $\mathrm{RGO} / \mathrm{Z} / \mathrm{ZF}$ with a larger surface area (see Table 2) which can make photocatalyst absorb more light radiation and dyes. ${ }^{37}$ Thirdly, there are a lot of defects and few excited groups containing oxygen in the RGO surface because of reduction of GO, which can bring strong absorption capacity for the RGO/Z/ZF. ${ }^{49}$ At last, the conjugated $\pi$ system of RGO can also hinder the recombination of electron-hole pairs. ${ }^{38}$ As a result, the $\mathrm{RGO} / \mathrm{Z} /$ ZF has high photocatalytic activity. 


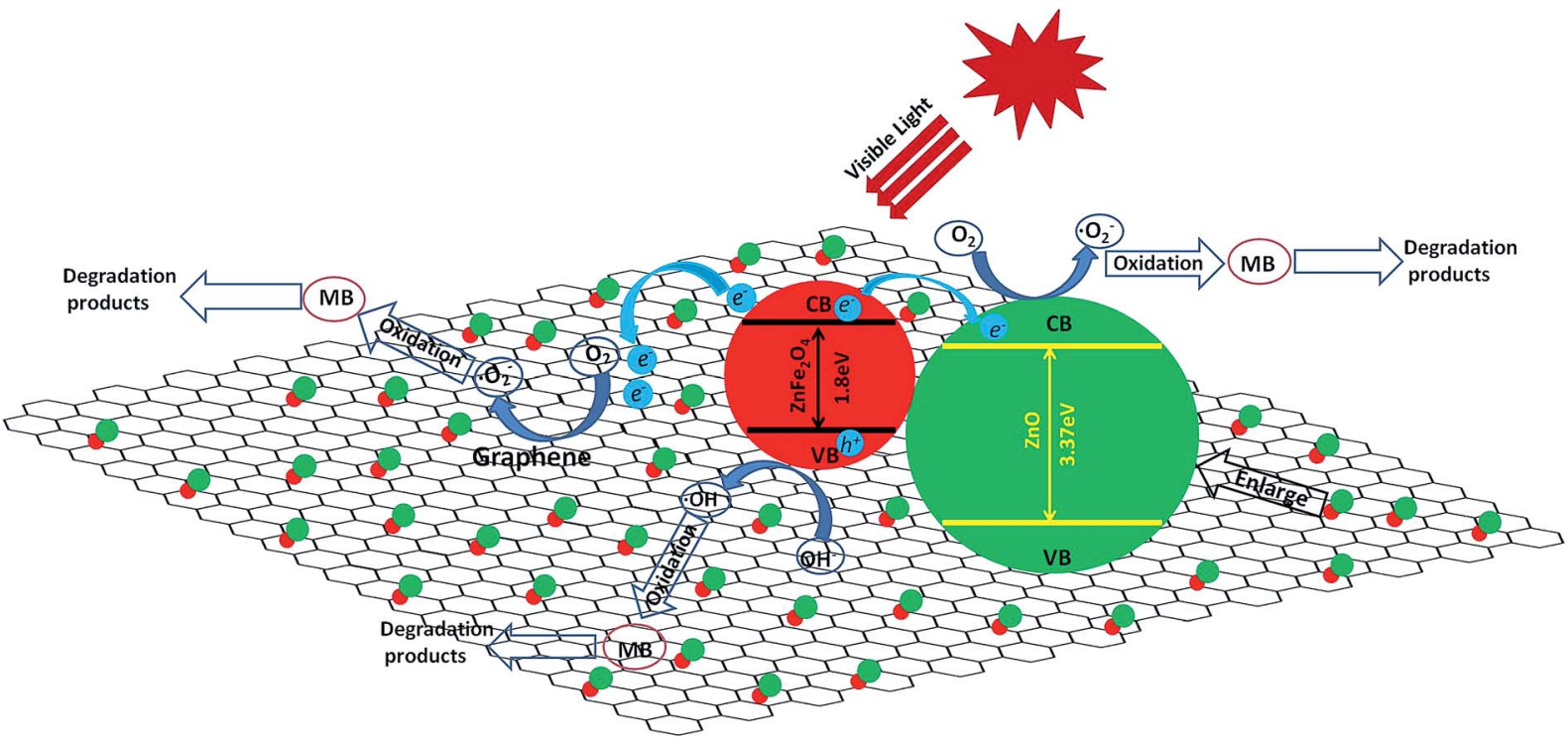

Fig. 9 Schematic diagram of possible photocatalytic mechanism of RGO/Z/ZF-3 composite under visible light irradiation.

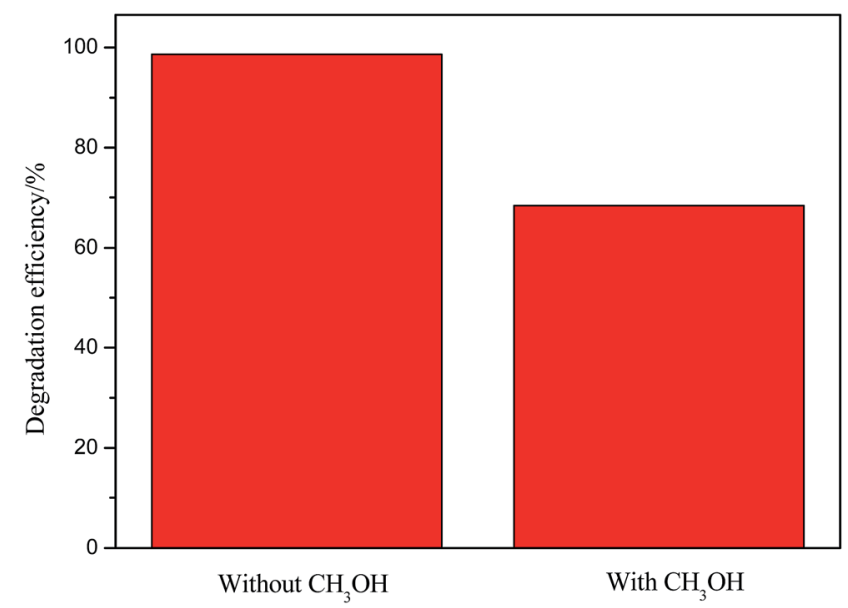

Fig. 10 Degradation efficiency of $\mathrm{RGO} / \mathrm{ZnO} / \mathrm{ZnFe}_{2} \mathrm{O}_{4}-3$ with or without $\mathrm{CH}_{3} \mathrm{OH}$.

Table 2 BET surface area of the samples

\begin{tabular}{ll}
\hline Samples & BET surface area $\left(\mathrm{m}^{2} \mathrm{~g}^{-1}\right)$ \\
\hline $\mathrm{Z}$ & 92 \\
$\mathrm{Z} / \mathrm{ZF}$ & 67 \\
$\mathrm{RGO} / \mathrm{Z} / \mathrm{ZF}-1$ & 127 \\
$\mathrm{RGO} / \mathrm{Z} / \mathrm{ZF}-3$ & 138 \\
$\mathrm{RGO} / \mathrm{Z} / \mathrm{ZF}-5$ & 154
\end{tabular}

\subsection{Reusability and stability of RGO/Z/ZF-3 composite}

The Fig. 11 showed the hysteresis loops of pure $\mathrm{ZnFe}_{2} \mathrm{O}_{4}(\mathrm{ZF})$ and $\mathrm{RGO} / \mathrm{Z} / \mathrm{ZF}-3$ composite. The narrow magnetic hysteresis loops of the samples indicate that the samples are magnetically soft with low coercivity. The saturation magnetization of RGO/Z/

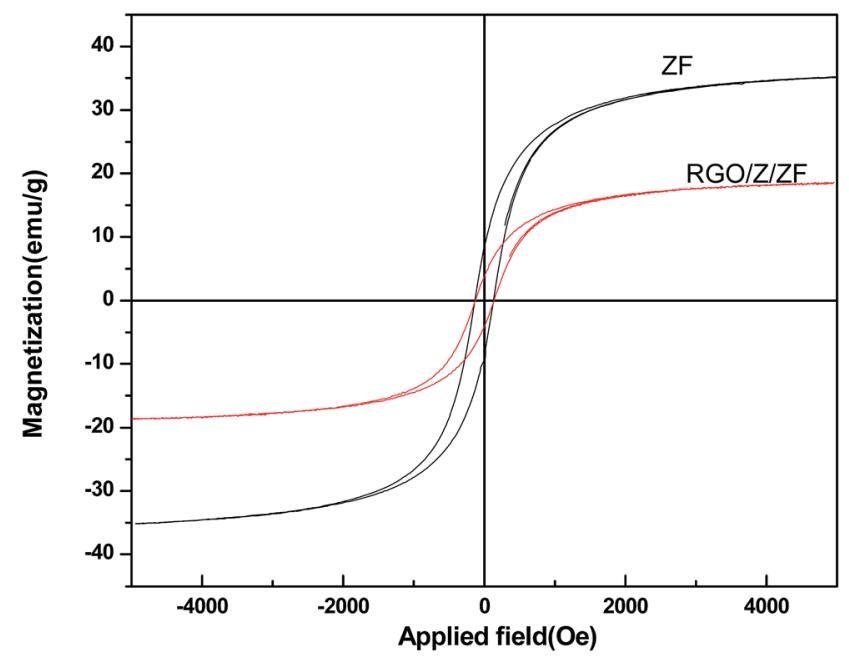

Fig. 11 The magnetization hysteresis loops of $\mathrm{ZnFe}_{2} \mathrm{O}_{4}(\mathrm{ZF})$ and $\mathrm{RGO} /$ Z/ZF-3 composite.

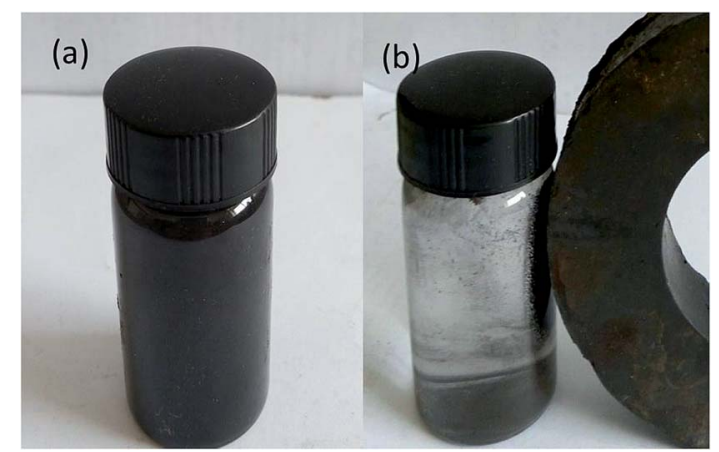

Fig. 12 Digital photographs of RGO/Z/ZF-3 collected by an external magnet (a) before separated; (b) after separated. 


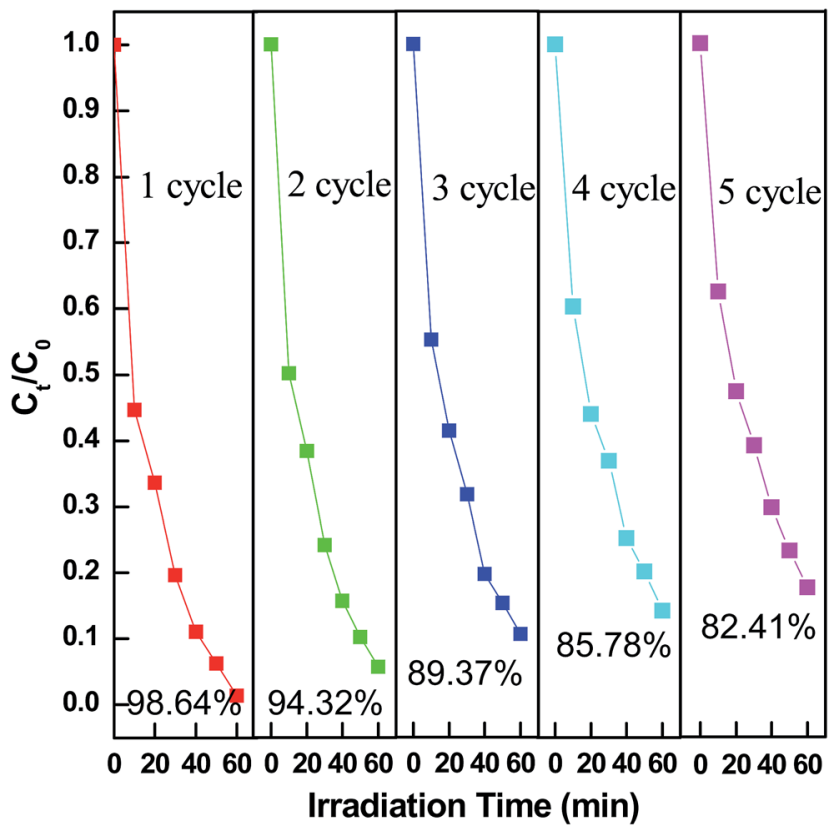

Fig. 13 Photocatalytic degradation of MB during five circulations using RGO/Z/ZF-3.

ZF-3 composite was clearly lower than that of single ZF, which may be due to the addition of nonmagnetic RGO and $\mathrm{ZnO}$. However, the saturation magnetization of $\mathrm{RGO} / \mathrm{Z} / \mathrm{ZF}-3$ composite is still enough to make it be separated from the degradation solution. The photograph of magnetic separation is shown in Fig. 12. The RGO/Z/ZF composite can be collected quickly by a magnet just for about $1 \mathrm{~min}$. The result of repeated photocatalytic experiments on RGO/Z/ZF-3 is given in Fig. 13. It can be seen from Fig. 13 that the photocatalytic activity of composite still gets $82.41 \%$ after five recycles, which suggests the excellent photocatalytic stability of RGO/Z/ZF-3.

\section{Conclusions}

RGO/Z/ZF composites were synthesized by two steps method. Z/ ZF composites with core-shell structure are coated by nearly transparent flake-like RGO. The composite shows excellent photocatalytic activity. RGO/Z/ZF-3 has not only the optimal photocatalytic activity because of its appropriate RGO content, heterojunction structure and special type II band alignment which can absorb more $\mathrm{MB}$ and improve the degradation of $\mathrm{MB}$, respectively, the ratio of degradation of $\mathrm{MB}$ is $98.64 \%$ when it was under visible light for $60 \mathrm{~min}$, but also enough stability to be reused.

\section{Notes and references}

1 D. Zhang and F. Zeng, J. Mater. Sci., 2013, 47, 2155-2161.

2 L. Zhang, L. Du, X. Yu, S. Tan, X. Cai, P. Yang, Y. Gu and W. Mai, ACS Appl. Mater. Interfaces, 2014, 6, 3623-3629.

3 K. Kumar, M. Chitkara, I. S. Sandhu, D. Mehta and S. Kumar, J. Alloys Compd., 2014, 588, 681-689.
4 A. A. Ashkarran and B. Mohammadi, Appl. Surf. Sci., 2015, 342, 112-119.

5 R. Shao, L. Sun, L. Q. Tang and Z. D. Chen, Chem. Eng. J., 2013, 217, 185-191.

6 C. L. Wang, X. Tan, J. T. Yan, B. Chai, J. F. Li and S. Z. Chen, Appl. Surf. Sci., 2017, 396, 780-790.

7 F. Liu, Y. Xie, C. Yu, C. L. Yu, X. M. Liu, Y. H. Dai, L. J. Liu and Y. Ling, RSC Adv., 2015, 5, 24056-24063.

8 Y. Xie, Y. Z. Li and X. J. Zhao, J. Mol. Catal. B: Enzym., 2007, 277, 119-126.

9 S. H. Xu, L. Fu, T. S. H. Pham, A. M. Yu, F. G. Han and L. Chen, Ceram. Int., 2015, 41, 4007-4013.

10 J. Y. Qu, L. Shi, C. H. He, F. Gao, B. B. Li, Q. Zhou, H. Hu, G. H. Shao, X. Z. Wang and J. S. Qiu, Carbon, 2014, 66, 485-492.

11 S. Wu, P. Wang, Y. Cai, D. Liang, Y. Ye, Z. Tian, J. Liu and C. Liang, RSC Adv., 2015, 5, 9069-9074.

12 Z. Chen, N. Zhang and Y. J. Xu, CrystEngComm, 2013, 15, 3022-3030.

13 Y. Fu and X. Wang, Ind. Eng. Chem. Res., 2011, 50, 7210-7218. 14 J. H. Luo, P. Sheng, W. Yao, C. F. Jiang and J. G. Xu, Nanoscale Res. Lett., 2016, 11, 141.

15 Y. Xu, J. H. Luo, W. Yao, J. G Xu and T. Li, J. Alloys Compd., 2015, 636, 310-316.

16 K. Singh, A. Ohlan, V. H. Pham, R. Balasubramaniyan, S. Varshney, J. Jang, S. H. Hur, W. M. Choi, M. Kumar, S. K. Dhawan, B. S. Kong and J. S. Chung, Nanoscale, 2013, 5, 2411-2420.

17 X. P. Shen, J. L. Wu, S. Bai and H. Zhou, J. Alloys Compd., 2010, 506, 136-140.

18 H. L. Guo, X. F. Wang, Q. Y. Qian, F. B. Wang and X. H. Xia, ACS Nano, 2009, 3, 2653-2659.

19 H. K. Jeong, Y. P. Lee, R. J. W. E. Lahaye, M. H. Park, K. H. An, I. J. Kim, C. W. Yang, C. Y. Park, R. S. Ruoff and Y. H. Lee, J. Am. Chem. Soc., 2008, 130, 1362-1366.

20 H. P. Cong, X. C. Ren, P. Wang and S. H. Yu, ACS Nano, 2012, 6, 2693-2703.

21 C. Z. Zhu, S. J. Guo, Y. X. Fang and S. J. Dong, ACS Nano, 2010, 4, 2429-2437.

22 P. Laokul, V. Amornkitbamrung, S. Seraphin and S. Maensiri, Curr. Appl. Phys., 2011, 11, 101-108.

23 Z. Jin, J. Yao, C. Kittrell and J. M. Tour, ACS Nano, 2011, 5, 4114-4117.

24 W. F. Chen, S. R. Li, C. H. Chen and L. F. Yan, Adv. Mater., 2011, 23, 5679-5683.

25 Y. Z. Xue, B. Wu, L. Jiang, Y. L. Guo, L. P. Huang, J. J. Chen, J. H. Tan, D. C. Geng, B. R. Luo, W. P. Hu, G. Yu and Y. Q. Liu, J. Am. Chem. Soc., 2012, 134, 11060-11061.

26 D. Z. Chen, G. S. Wang, S. He, J. Liu, L. Guo and M. S. Cao, J. Mater. Chem. A, 2013, 1, 5996-6003.

27 D. L. A. Faria, S. V. Silva and M. T. Oliveira, J. Raman Spectrosc., 1997, 28, 873-878.

28 X. D. Guo, R. X. Li, Y. Hang, Z. Z. Xu, B. K. Yu, H. L. Ma and X. W. Sun, Mater. Lett., 2007, 61, 4583-4586.

29 L. B. Yang, Y. Zhang, W. D. Ruan, B. Zhao, W. Q. Xu and J. R. Lombardi, J. Raman Spectrosc., 2010, 41, 721-726. 
30 X. Zhou, B. Wang, H. Sun, C. Wang, P. Sun, X. Li, X. Hua and G. Lu, Nanoscale, 2016, 8, 5446-5453.

31 D. Andreeva, T. Tabakova, V. Idakiev, P. Christov and R. Giovanoli, Appl. Catal., A, 1998, 169, 9-14.

32 S. Wang, J. Zhang, J. Yang, X. Gao, H. Zhang, Y. Wang and Z. Zhu, RSC Adv., 2015, 5, 10048-10057.

33 H. C. Schniepp, J. L. Li, M. J. McAllister, H. Sai, M. HerreraAlonso, D. H. Adamson, R. K. Prud'homme, R. Car, D. A. Saville and I. A. Aksay, J. Phys. Chem. B, 2006, 110, 8535-8539.

34 D. C. Luo, G. X. Zhang, J. F. Liu and X. M. Sun, J. Phys. Chem. C, 2011, 115, 11327-11335.

35 J. Jang, S. Hong, J. Lee, P. H. Borse, O. S. Jung, T. Hong, E. Jeong, M. Won and H. Kim, J. Korean Phys. Soc., 2009, 54, 204-208.

36 D. Hu, Y. Xie, L. Liu, P. P. Zhou, J. Zhao, J. W. Xu and Y. Ling, Appl. Catal., B, 2016, 188, 207-216.

37 L. Zhang, L. H. Du, X. Cai, X. Yu, D. D. Zhang, L. C. Liang, P. H. Yang, X. B. Xing, W. J. Mai, S. Z. Tan, Y. Gu and J. H. Song, Phys. E, 2013, 47, 279-284.

38 J. T. Feng, Y. H. Hou, X. Y. Wang, W. L. Quan, J. M. Zhang, Y. C. Wang and L. C. Li, J. Alloys Compd., 2016, 681, 157-166.
39 A. H. Mady, M. L. Baynosa, D. Tuma and J. J. Shim, Appl. Catal., B, 2017, 203, 416-427.

40 L. Sun, R. Shao, L. Q. Tang and Z. D. Chen, J. Alloys Compd., 2013, 564, 55-62.

41 X. Li, D. Tang, F. Tang, Y. Zhu, C. He, M. Liu, C. Lin and Y. Liu, Mater. Res. Bull., 2014, 56, 125-133.

42 M. Gratzel, Nature, 2001, 414, 338-344.

43 X. Y. Li, Y. Hou, Q. D. Zhao and G. H. Chen, Langmuir, 2011, 27, 3113-3120.

44 S. H. Cho, J. W. Jang, J. W. Kim, J. S. Lee, W. Y. Choi and K. H. Lee, Langmuir, 2011, 27, 10243-10250.

45 X. Guo, H. J. Zhu and Q. Li, Appl. Catal., B, 2014, 160-161, 408-414.

46 H. J. Zhang, G. H. Chen and D. W. Bahnemann, J. Mater. Chem., 2009, 19, 5089-5121.

47 T. Ichino and R. W. Fessenden, J. Phys. Chem. A, 2007, 111, 2527-2541.

48 D. F. Xu, B. Cheng, S. W. Cao and J. G. Xu, Appl. Catal., B, 2015, 164, 380-388.

49 J. H. Shen, G. Ma, J. M. Zhang, W. L. Quan and L. C. Li, Appl. Surf. Sci., 2015, 359, 455-468. 